\title{
A ALIENAÇÃO MENTAL E SUAS (RE)PRODUÇÕES NA CONTEMPORANEIDADE
}

\author{
Leandro Anselmo Todesqui Tavares ${ }^{1}$, Francisco Hashimoto ${ }^{2}$ \\ ${ }^{1}$ Unesp-Assis - SP. ${ }^{2}$ Docente do Programa de Pós-Graduação em Psicologia na UNESP - Faculdade de Ciências e Letras de Assis.
}

\begin{abstract}
RESUMO
O presente ensaio propõe uma reflexão partindo do conceito de "alienação mental" forjado no decorrer do séc.XVIII, momento em que a loucura é denominada e reconhecida como doença mental. A alienação mental é entendida então como um produto das práticas que agiam sobre a loucura, fruto do atravessamento realizado por determinadas formas de Saber/Poder, implicando intervenções que atuavam por meio de dispositivos institucionais que produziam determinadas formas de subjetivação delineando-a como necessariamente psicopatológica. Compreendendo o processo de atravessamento que a loucura sofre pelos paradigmas psiquiátricos propõe-se, desta forma, pensar sobre os dispositivos alienadores na atualidade, em especial as práticas oriundas dos modelos bio-médicos com relação à subjetividade, incluindo aí a crescente medicalização indiscriminada dos indivíduos.

Palavras-chave: Alienação Mental; Medicalização; "Mal-Estar"; Contemporaneidade.
\end{abstract}

\section{A MENTAL AND SALE (RE) PRODUCTION IN THE CONTEMPORARY}

\begin{abstract}
This paper reflects starting with the concept of "insanity" forged during the XVIIIth century when the madness is known and recognized as mental illness. The insanity is then understood as a product of the practices that worked on the madness, the result of crossing held by some forms of knowledge and power, involving interventions that operate through institutional arrangements that produced certain forms of subjectivity outlining it as necessarily psychopathological. Understanding the process of crossing the madness suffered by psychiatric paradigms is proposed, therefore, think about the alienating devices today, especially those practices coming from the biomedical models with respect to subjectivity, including therein the increasing medicalization of indiscriminate individuals.
\end{abstract}

Keywords: Alienation Mental, Medicalization, "malaise"; Contemporary. 


\section{INTRODUÇÃO}

O que tornaria legítimo pensarmos em uma modalidade de "alienação subjetiva" na atualidade, tendo em vista que o seu correlato conceitual - a "alienação mental" - diz respeito aos modos específicos de se compreender a loucura nos séc. XVII e XVIII?

Sob qual tênue horizonte avistamos a perpetuação de condições de "mal-estar", os quais num dado momento foi representado pelo signo da "doença mental", e como se dariam suas (re)produções na contemporaneidade?

Se naquela época a loucura adquiriu o status de doença mental (reconhecida pelos saberes que the atravessavam), em nossos dias são variadas as políticas de saúde e movimentos sociais que lutam em prol da inclusão dos pacientes em sofrimento psíquico nos espaços da cultura e da sociedade de forma geral. Partindo da Reforma Psiquiátrica ao Movimento da LutaAntimanicomial, colhemos alguns frutos (ainda em construção) de conquistas que se acumulam ao longo dos anos no sentido de humanizar o tratamento de pacientes, ao mesmo tempo em que se promovem uma reconfiguração da representação social sobre a loucura. Trata-se da construção paulatina de uma nova cultura e modos de apreender e conviver com todos os pacientes que se encontram em situações de sofrimento psíquico.

Contudo, se na atualidade avançamos em direção a um tratamento mais humanizado em todos os sentidos, na mesma medida podemos constatar outro efeito paradoxal típico da contemporaneidade, à saber, a medicalização indiscriminada das subjetividades.

Notemos que atualmente diagnósticos como os de depressão, pânico, e tantos outros se tornaram jargões banalizados, implicando que na maioria das vezes nossos pacientes chegam até nós já diagnosticados e medicados. Esta tendência na contemporaneidade de medicalizar os afetos (e inclusive sentimentos comuns $\mathrm{e}$ intrínsecos às condições de seres desejantes), como podemos perceber por meio de nossa prática clínica exercida no âmbito da Saúde Pública, nos faz refletir sob quais os possíveis efeitos de tais diretrizes terapêuticas na atualidade. Algumas questões são evidentes, como por exemplo, a intolerância ao sofrimento que subjaz implícita nas terapêuticas exclusivamente medicamentosas, traduzindo numa aposta única no apaziguamento dos afetos e sentimentos mais diversos. Acompanhado disto temos os variados diagnósticos que indicam uma condição necessariamente patológica no indivíduo que vivencia uma situação de sofrimento.

Ante o entrecruzamento de questões crucias como estas, naquilo que diz respeito às formas de se lidar com o "mal-estar" na contemporaneidade, lançamo-nos na busca de tentar compreender as possíveis configurações de perpetuação e/ou saídas possíveis para as condições de sofrimento na atualidade.

\section{A LOUCURA COMO DOENÇA MENTAL}

$$
\begin{array}{r}
\text { "Eu fico louco, eu fico fora-de-si } \\
\text { Eu fica assim, eu fica fora de mim } \\
\text { Eu fico um pouco, depois eu saio daqui } \\
\text { Eu vai embora, eu fico fora-de-si } \\
\text { Eu fico oco, eu fica bem assim } \\
\text { Eu fico sem ninguém em mim" } \\
\text { (Arnaldo Antunes, 1995) }
\end{array}
$$

Na passagem do séc. XVII ao XVIII a loucura ganha o status de alienação mental, sendo então considerada como necessariamente uma "doença mental". Um mal que abate o sujeito privando-lhe das faculdades da razão, caracterizando-o como que entregue às malhas do desatino e dos desejos desenfreados, indivíduo que não pode ser responsabilizado por seus atos dado sua incapacidade de julgamento sobre si mesmo e sobre as coisas do mundo de uma forma geral. É em torno desta concepção que as práticas Psiquiátricas vão se delineando como dispositivos alienantes sobre loucura neste período. A partir desta pré-concepção sobre a doença mental é que 
vão se construindo as maneiras bem especificas e características desta época de se intervir sobre estes estados.

Ao mesmo tempo em que os hospitais Psiquiátricos tornam-se um lugar privilegiado para a construção do saber sobre a loucura, estes atuam também como dispositivos institucionais e, principalmente, como produtores de realidades, como diz Foucault (2005), no sentido de que se produzem determinadas subjetivações a partir de sua prática. Todo o aparato conceitual e estratégico de se intervir sobre a loucura, incluindo aí o internamento e isolamento como marcos principais, produzem a própria alienação mental que tinham como intenção curar. A figura do médico é identificada como o "mestre da loucura", detentor do saber sobre estas condições, figura de autoridade suprema sobre o conhecimento das etiologias e das formas de tratamento para os doentes da época.

Toda esta visão, impregnada em seu âmago de preceitos morais, destinava à loucura um lugar de erro, de desvio de conduta, uma caricatura do sem-sentido, uma vez que o louco não poderia responder de forma adequada e aceitável às normas sociais. Fica claro que neste período a loucura se enunciava especificamente pela descrição de um estado em que se atribuía ao sujeito as características de um estar "fora-desi".

Ao considerar o sofrimento psíquico sob esta ótica, justificava-se o internamento para o Saber da época, como forma de isolar o louco do restante da sociedade, a fim de lhe assegurar um espaço sem interferências do meio externo que não alterassem as observações médicas, ao mesmo tempo em que resguardaria a sociedade do contato desagradável e perigoso com o louco. Perigoso, pois a doença mental foi durante muito tempo comparado à criminalidade:

\footnotetext{
Existem assim afetos considerados perigosos, que por sua intensidade e violência podem impossibilitar este equilíbrio da rede das inter-relações
}

pessoais, isto é, a sociabilidade. Estes são as paixões, que impulsionam o indivíduo com uma tal violência, rompendo com os seus controles, que levam-na a perda da razão. No individuo, o que impediria que o afeto se tornasse paixão seria a vontade, que funcionaria como instância reguladora da afetividade. (BIRMAN, 1978, p. 37).

É evidente que neste período o parâmetro de comparação e alicerce em que se apoiavam as concepções de normal e patológico estava intrinsecamente ligado às noções de razão/juízo. A razão, aqui, é considerada como um bem elevado da condição humana, um dos atributos altamente valorizados do homem social que por intermédio do juízo e da vontade pode controlar seus impulsos e desejos.

A loucura, em toda sua história sempre teve seu lugar pouco definido, e assim, em pleno séc. $X V I I$ e $X V I I I$, os asilos e prisões tinham em seu contingente toda uma mistura de sujeitos alocados num mesmo lugar, sendo identificados sob os mesmos rótulos, independente das suas naturezas distintas. Misturavam-se os loucos com os doentes da lepra, com os indigentes, os desabrigados, os estrangeiros, os abandonados, os vagabundos, os mal-feitores, etc. e também com os criminosos causadores de delitos. Provém daí a co-relação da loucura com a periculosidade enquanto um potencial criminoso que põe em risco toda a sociedade de uma forma geral.

Todos estes detalhes, que regem o imaginário social e especializado sobre a loucura neste período, destinam ao sofrimento psíquico o isolamento como medida mais eficaz para se tratar deste mal e, ao mesmo tempo, proteger a sociedade comum da periculosidade dos doentes. Como Birman nos aponta, "[...] a cura psiquiátrica é essencialmente um tratamento moral [...]". Toda a ordenação dos loucos num espaço controlado, num ritmo controlado, tem por objetivo efetivar o controle das paixões e dos afetos. "O asilo é um instrumento de instituição de normas morais" (BIRMAN,1978, p. 35). 
O desenvolvimento da medicina social no séc. XVIII é caracterizado fundamentalmente pelas medidas de quarentena e pelos mecanismos de exclusão implícitos neste processo, que tinham por objetivo isolar os doentes para assim proteger o espaço público das mazelas das doenças. É o sonho político-médico da purificação do espaço urbano que as medidas de quarentena visavam concretizar. Como não poderia ser diferente, a psiquiatria se desenvolve dentro dos mesmos axiomas da medicina característica desta época, e é dentro desta perspectiva que a loucura se vê aprisionada nas casas de internamento, asilos e hospitais gerais.

Nestas condições, a Psiquiatria muito antes de atuar como um campo de produção de conhecimento e Saber sobre determinado objeto, no caso, a doença mental, antes, viabiliza um ideal de higienização pública, a purificação do espaço social:

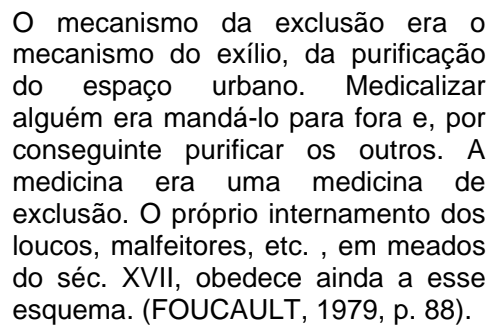

A prática do isolamento além de resguardar o espaço urbano do patógeno em potencial, tinha também o intuito de criar um lócus de observação, estudo, sistematização e produção de saber sobre as doenças. No caso das doenças mentais é o "jardim das espécies", assim designado por Foucault em sua Historia da Loucura, o lugar de conhecimento das doenças mentais, bem como lugar também de sua produção propriamente dita.

A medicina psiquiátrica deste período isola o louco por este ser considerado sofredor da alienação mental. A loucura dentro deste conceito era representada e entendida como uma desrazão, um não-ser, um abalo das paixões e dos afetos que atentavam contra a razão do doente, privando-o assim dos atributos norteadores da racionalidade encontrada então nos indivíduos ditos "normais". Neste sentido, a loucura ganha o status de desatino, uma vez que é relacionada à dimensão do erro, do falso, do sem juízo, e em última instância do completo sem-sentido. O sujeito doente, por este viés, não pode sequer responder por suas responsabilidades, uma vez que está fora-de-si, fora do campo norteador e controlador da razão.

Assim, todo o discurso sobre a loucura que é construído pela medicina psiquiátrica desta época, coloca em evidência necessariamente uma dimensão negativa da expressão da loucura. Não é possível considerá-la em termos de positividade de alguma expressão sobre a condição humana, antes apenas, é considerada toda sua expressão enquanto negatividade, uma vez que esta sempre é comparada com os primados da razão. Tudo que é subtração, erro, desajuste de costumes e comportamentos socialmente aceitos, estranho, incompreensível sob o olhar médico (mestre da loucura) é catalogado como alienação mental e, subsequentemente esquadrinhado nos diversos tipos e formas de doenças mentais.

Neste sentido o hospital passa a ser um espaço de controle dos alienados. É neste cenário que a Psiquiatria do séc. XVIII se esforça por desvendar a verdade sobre a loucura, uma ambição médica que tem como pressupostos norteadores o isolamento do louco, a observação dentro de um contexto controlado e a descrição sistemática dos dados. Os dispositivos implicados nesse processo acabam por produzir a própria alienação mental, um regime sistemático de condicionamentos a que os doentes eram submetidos: controle do espaço, do vestuário, da alimentação, proibição de hábitos inadequados para o sistema, punições com duchas etc. e, por fim, o controle do tempo, talvez a mais cruel e alienante estratégia de controle. Como se não bastassem os eventuais sofrimentos do sujeito em 
questão, o contexto e as práticas de cura comum a este período sem dúvida potencializavam e patologizavam ainda mais os doentes, pois a doença em si, tal como era definida pelo saber médico, era indubitavelmente produzida por estes detentores do conhecimento.

Fazendo uso da analogia de Foucault utilizada na "História da Loucura", podemos comparar estes dispositivos psiquiátricos a um grande jardim botânico, ou como o próprio autor denomina a construção de um verdadeiro "jardim das espécies": isolar para estudar sem interferências externas o fenômeno em si, uma tentativa de neutralidade extrema e ingênua que tinha repercussões diretas na subjetividade desses doentes:

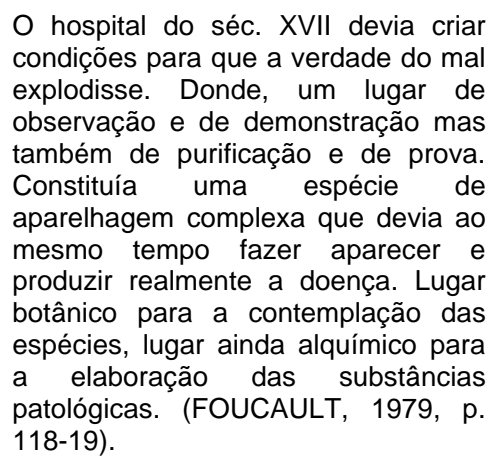

Do ventre destas práticas que produzem determinadas formas de subjetivação, bem como realidades, nascem as concepções nosológicas, meramente descritivas e pobremente explicativas qualitativamente. Um verdadeiro "catálogo das espécies" - enquadrando o ser em categorias e sub-categorias, e ao mesmo tempo uma sistematização que dá ao médico o status de mestre da loucura nos séc. XVIII e XIX. O Psiquiatra ocupava então, desde o início, um lugar de autoridade inquestionável sobre o estatuto da loucura, o que de fato, dentro da rede hierarquizada dos Hospitais já era um dispositivo de alienação, dada a discrepância entre a figura do médico e do louco. O louco como personagem desprovido de razão era designado a uma função de total submissão em relação à figura do médico.
Submissão alienante, pois este cenário é a re-produção da concepção prévia sobre a loucura como um fora-de-si. O saber valorativo sobre a loucura a concretiza como um não-ser, uma desrazão, incapacidade de discernimento, uma falta do juízo crítico e racional, e assim, o lócus hospitalar implica as relações de Poder desiguais entre médicos e alienados. Os alienados como desprovidos da razão submetidos à figura do médico detentor supremo do Saber sobre a loucura. Como nos diz Foucault (1979, p. 122), o conjunto de técnicas e procedimentos efetuados nos asilos do séc. XIX tinha por função fazer do personagem do médico o "mestre da loucura", aquele que, em sua prática, "[...] a faz se manifestar em sua verdade quando ela se esconde, quando esta permanece silenciosa e soterrada, e aquele que domina, acalma e absorve depois de tê-la sabiamente desencadeado".

Toda esta concepção da loucura e da doença mental de uma forma geral, jamais considera o fenômeno em sua dimensão positiva, ao contrário, o discurso do Saber Psiquiátrico constrói um objeto que é contemplado pelo viés da negatividade. Assim atribuí-se ao louco uma série de faltas, incapacidades e inaptidões - a alienação mental atrela-se a noção de desatino excluindo assim qualquer possibilidade de considerar-se um Sujeito:

[...] a loucura está sempre ausente, num eterno retiro onde ela é inacessível, sem fenômeno nem positividade. E no entanto ela está presente e perfeitamente visível sob as espécies singulares do homem louco. Ela, que é desordem insensata, quando examinada revela apenas espécies ordenadas, mecanismos rigorosos na alma e no corpo, linguagem articulada segundo uma lógica visível. Tudo é razão naquilo que a loucura pode dizer sobre si mesma, ela que é negação da razão. Em suma, uma apreensão racional da loucura é sempre possível e necessária, na exata medida em que ela é não-razão. (FOUCAULT, 2005, p. 243).

Estes indivíduos, os alienados, teriam então uma total fragilidade da ordem da vontade, e 
isto os tornariam incapazes de represarem seus impulsos mais bestiais e hostis restando-lhes apenas obedecê-los cegamente. Assim eles teriam perdido sua liberdade, não podendo de forma alguma serem considerados como responsáveis por suas ações. Esta completa insensatez dos alienados, justifica para o Saber Psiquiátrico da época o internamento asilar como medida mais eficaz para a cura. O Saber Psiquiátrico atua então como um dispositivo normatizador dos indivíduos, definido como recuperador das individualidades que se desviaram do exercício de normas estabelecidas socialmente. Contudo, não é simplesmente a cura que visam as práticas em cuidado aos loucos neste período, como se fosse um ideal romântico ou um Bem altruísta que se fizessem aos doentes, mas sim, visam um verdadeiro exercício de poder sob aqueles que estavam em sofrimento psíquico, e que, segundo a ótica dominante, ofereciam riscos a sociedade. Mesmo porque, o que estava em questão o tempo todo eram as comparações entre os doentes e os ditos "normais", uma parâmetro de normalidade totalmente subsidiado por um discurso demasiadamente moralizante e civilizador, que visava o adestramento de subjetividades e modos de ser e estar no mundo.

\section{A ALIENAÇÃO NA ATUALIDADE}

"E se não tivesse o amor? $E$ se não tivesse essa dor?

$E$ se não tivesse o sofrer? E se não tivesse o chorar?" (Caetano Veloso, 1972)

Como sabemos, nos dias de hoje grandes esforços viabilizam a extinção progressiva de manicômios e instituições de reclusão, sendo estes substituídos por serviços alternativos que não efetuam o internamento, como os Centros de Atenção Psicossocial (Caps) e os Núcleo de Apoio Psicossocial (Naps) no Brasil especificamente, além de outros projetos sociais governamentais ou, na sua falta, iniciados e incentivados pelo terceiro setor. Apesar de muito faltar para a concretização stricto sensu de uma reforma psiquiátrica verdadeira, o Brasil é um dos países com o menor número de leitos psiquiátricos no mundo.

Por conta disso, será apontado aqui formas mais sutis de alienação na atualidade, como é o caso das que se fazem pela excessiva medicalização dos indivíduos e do social de uma maneira geral.

Tornou-se comum as pessoas fazerem uso de psicofármacos para os mais variados tipos de desconfortos emocionais, angústias, ou outras formas de "mal-estar" psíquico, a ponto de o consumo de tranqüilizantes e antidepressivos ter se constituído como algo banal.

A psicopatologia na contemporaneidade ganhou classificações, categorias e sub-categorias nosológicas, as quais encontramos nos manuais de psiquiatria vigentes - DSM IV e CID-10. Evidentemente, esta nosologia reflete uma concepção essencialmente biológica, uma herança da Psiquiatria clássica, como foi apontado anteriormente no texto. Tornou-se algo corriqueiro e comum a ploriferação de diagnósticos de depressão (incluindo aí as diversas classificações de tipos e sub-tipos) e das síndromes do pânico, para citarmos os mais freqüentes.

É claro e comumente sabido, que, tais diagnósticos formulados com base numa simples leitura sintomatológica (semiologia dos transtornos mentais), uma sistematização e registro dos sintomas manifestos, tem como sua finalidade orientar uma prescrição medicamentosa para tais casos. Não vem ao caso aqui desconsiderarmos a importância e utilidade dos psicofármacos, principalmente nas situações de psicoses onde o controle dos surtos freqüentes é de muita ajuda aos pacientes. Porém, a medicalização indiscriminada de pacientes rotulados como "depressivos" e "panicados" é um problema de 
outra natureza. Primeiro, porque estas duas categorias aqui selecionadas para reflexão, retratam de certa forma, estados afetivos muito característicos da própria condição humana. Depressão e Angústia (pânico) são afetos originários do psiquismo humano, e sendo assim, essa é uma condição demasiadamente relativa no momento de formular-se um diagnóstico patológico que se baseia nestes sentimentos.

O que percebemos hoje em dia é uma tendência avassaladora em se patologizar esses afetos, identificando como doente quem é acometido por tais sensações. Eis então o diagnóstico atuando aqui como um dispositivo de alienação do sujeito, produzindo assim formas específicas de subjetivação.

O paciente, ao receber este rótulo de um médico na maioria das vezes (Sujeito Suposto Saber na relação transferencial) identifica-se automaticamente, e internaliza esta condição. A partir deste momento o indivíduo realmente sofre daquilo que Ihe foi dito, pois este pôde obter através do diagnóstico um nome que cobre seu não-saber sobre seu mal-estar. No lugar de um saber-sobre-si, que poderia acontecer mediante um processo de análise, por exemplo, o paciente é (re)coberto por um significante (depressão/pânico) que lhe isenta da necessidade de compreensão subjetiva sobre sua condição. Este rótulo/diagnóstico, que nos dias atuais é carregado de uma determinada representação social provinda do Saber médico, o qual considera estes estados como algo necessariamente doentio, ratifica estes afetos como se fosse um vírus que viria de fora do sujeito. Tal como uma moléstia que adentra o organismo, esta é então tratada medicamentosamente, como para uma gripe em que se tomam antibióticos e antiinflamatórios.

Convém lembrarmos também que, tal como nossa experiência profissional nos confirma, os pacientes diagnosticados como "depressivos", por exemplo, possuem em comum algumas particularidades no que diz respeito às tentativas de lidar com seu sofrimento no âmbito das assistências em Saúde. Como podemos observar, existe uma forma padronizada de (ex)-sistência destes sujeitos a partir do momento em que lhes atestam o diagnóstico de depressão, isso como consequência direta do também padronizado diagnóstico e tratamento que lhes sucede. O que nos chama a atenção é o fato de que alguns destes pacientes, uma vez diagnosticados como depressivos e (in)devidamente medicados, perdem grande capacidade de abertura para uma psicoterapia e, quando em algum momento nelas apostam, trazem em sua queixa uma evidente insatisfação com relação à "vida medicalizada".

Dois aspectos específicos emergem como fator comum na maioria dos casos: a queixa sobre o próprio sofrimento somada à queixa de que o uso de medicamentos se tornou insatisfatório; e a queixa de que mesmo medicados o "mal-estar" não cessa completamente, ou ainda, que outras sensações vieram constituir um "mal-estar" diferente do sofrimento inicial (aquele antecedente do período de medicação).

A alienação aqui, diz respeito então a uma impossibilidade de tornar-se um Sujeito de sua condição, uma vez que o rótulo definidor de um estado "doentio e anormal" pressupõe que aquele que sofre de tais sentimentos não precise comprometer-se ativamente num processo de compreensão subjetiva sobre si, basta aguardar passivamente os efeitos dos psicofármacos.

Obviamente, os axiomas da medicina atual estão em plena sintonia com a "cultura espetacular" vigente de nossos dias. Num cenário concebido como "espetáculo" (Debord, 1997), o eu ganha toda evidência e primazia, existindo e fazendo-se existir para um Outro. Este Outro, identificamos aqui como o discurso social imposto pelos veículos de comunicação e de mídia, que estimulam e demandam do sujeito uma performance espetacular, onde não se pode existir 
falhas, as quais ganham o significado de fraqueza/fracasso para o sujeito pós-moderno. Em suma, a ideologia dominante não tolera os "forade-moda", estes aquém dos signos brilhosos da cultura do espetacular, e neste cenário, os deprimidos e panicados são pessoas que não podem participar efetivamente destas demandas sócio-culturais.

Temos então, um discurso social vigente impregnado de uma ideologia que não tolera o sofrimento, tal como ocorrera nos séc. XVII e XVIII, porém agora esta se apresenta de acordo com 0 semblante característico da contemporaneidade, perpetuando-se as condições de "mal-estar" através do uso e abuso indiscriminado de psicofármacos. No ritmo acelerado da atualidade, é tirado do sujeito o direito de vivenciar lentamente suas tristezas e angústias. Como a ideologia dominante pressupõe acontecimentos rápidos, relacionamentos rápidos e acúmulo de experiências relâmpagos e vazias de significado, com o sofrimento humano não poderia ser diferente. Aqui entra em cena a função "milagrosa" dos tranqüilizantes e anti-depressivos na atualidade:

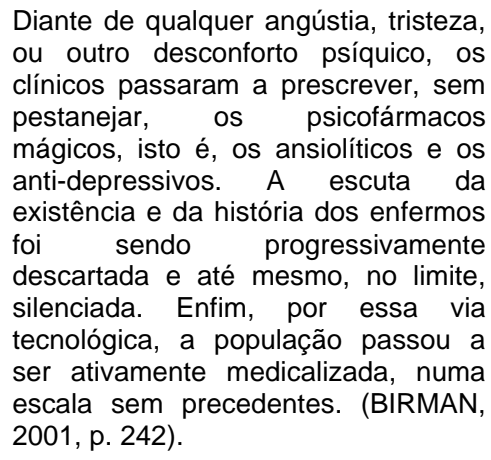

Este período específico que vivemos, o qual alguns autores denominam como pósmodernidade (Bauman, 1998), em si já é repleto de discursos alienantes. Toda a estimulação para o consumo de determinados produtos, estes que por sua vez representam ideais, sonhos, etc., desconsidera completamente a singularidade dos sujeitos, condenando a um lugar de fracasso o indivíduo que não pode, ou simplesmente não deseja, consumir desta cultura sufocante em andamento.

Ou seja, como em todos os períodos da história do homem, que sempre houve um ideal de normalidade, o que é aceitável perante uma maioria, o bem e o mal, hoje em dia não é diferente. No momento em que o homem desenvolve a linguagem, criando assim símbolos que os passam a representá-lo, criou também modos específicos de ser e estar no mundo. A norma, a regra e os costumes de uma forma geral, sempre específicos e bem caracterizados pelos dispositivos históricos de seu momento particular pressupõem maneiras valorizadas de ser e formas de conduta.

No caso de nossa atualidade pósmoderna, os pressupostos indivíduos devem estar em consonância com nosso tempo e sua lógica intrínseca. Formas específicas de condutas e posicionamentos na cena social são estimulados e, desta forma, a cultura cria um sistema de valoração para a performance do sujeito pósmoderno, atribuindo-Ihe categorias de valores desde o normal/esperado ao anormal/deplorável. Obviamente, o sistema de valores vigentes cria as próprias concepções de normal e patológico, com base nas tendências de uma maioria massificada pela cultura produzida na atualidade.

Sendo assim, o normal em si e à priori não existe, uma vez que o conceito de normalidade pressupõe o enquadramento do indivíduo nas categorias majoritárias de seu tempo:

[...] a norma é portadora de uma pretensão ao poder. [...] a norma traz consigo ao mesmo tempo um princípio de qualificação e um princípio de correção. A norma não tem por função excluir, rejeitar. Ao contrário, ela está sempre ligada a uma técnica positiva de intervenção e de transformação, a uma espécie de poder normativo. (FOUCAULT, 2001, p. 62).

Toda normatização, pressupõe então, um enquadramento dos indivíduos dentro de 
determinados padrões valorizados por uma determinada cultura. No caso da atualidade, este cenário impõe ao sujeito a obrigação das realizações das performences espetaculares a todo tempo. Estas performances espetaculares podem ser entendidas como um posicionamento, no sentido de uma estética das aparências sempre endereçadas ao Outro. Assim todos podem e devem ter seus "quinze minutos de fama", seja no corpo-a-corpo ou no universo virtual. Dos reality shows aos perfis cibernéticos, o que vemos é a exacerbação do eu para mostrar-se ao Outro.

Desta forma, a cultura espetacular é a précondição para uma performance demasiadamente narcísica. Ainda nos trâmites da cultura pósmoderna, outros valores são altamente estimulados, como por exemplo, a fluidez dos relacionamentos, a capacidade de permearmos quanto mais territórios possíveis, agilidade, desembaraço no relacionar-se, acúmulo de experiências em detrimento da qualidade das mesmas, etc.

De uma forma geral, a atualidade como descrita nos termos aqui apresentados, propiciam formas de subjetivação que sugerem sentimentos de depressão e angústia. Isto porque, a velocidade e a fluidez efêmera das múltiplas experiências e possibilidades, colocam o sujeito em maior contato com sua condição de desamparo, dado a forte quota de frustração a que estamos submetidos na contemporaneidade. $O$ próprio sistema capitalista já é em si propiciador de desamparo, uma vez que "promete" ideais e, no entanto, só uma pequena parcela da população com poder de compra pode usufruir disto. Dadas às características da atualidade, podemos dizer que o sujeito está exposto ao desamparo de uma maneira forte e intensa.

Compreendemos que tais terapêuticas destinadas a tratar os mais variados sofrimentos na atualidade e especificamente a depressão são, em última instância, o reflexo de nosso substrato cultural forjado na contemporaneidade. Se tais terapêuticas podem exercer sua força conduzindo muitas vezes diferentes sujeitos a modos padronizados de lidar com suas condições de sofrimento, isso só se torna possível na medida em que as condições culturais e ideológicas vigentes figuram como condição de possibilidade primeira para tal fato.

Assim, entendemos que a medicalização abusiva, indiscriminada e banalizada do sofrer humano só constitui-se como possibilidade e como tendência dominante numa sociedade que evidentemente carece de recursos outros para lidar com suas condições de sofrimento. Trata-se da construção de uma cultura com relação ao sofrer que, evidentemente, não está em si fatidicamente privada de tais condições, mas mais especificamente uma cultura que opta por apostar suas fichas nos encantos tecnológicos prometidos pelo mundo novo em detrimento dos movimentos simbólicos que suscitam a idéia, muitas vezes, de rudimentar e ultrapassado em pleno século XXI.

Hoje, o que podemos perceber então como corpo de Saber dominante sobre as práticas em Saúde voltado às questões de Saúde Mental, é a solidificação de dispositivos que não toleram o mínimo de sofrer. O indivíduo que, na sua maioria procura os serviços públicos de saúde, desconhece totalmente o sentido subjetivo que determinado "mal-estar" faz em seu espectro de existência particular. Contudo, devido aos discursos vigentes sobre o que é "estar bem" e "ser legal" nos dias de hoje, o sujeito já tem uma representação social de uma dita "normalidade". Isso tornou a representação de qualquer sofrimento como sendo algo que se deve ter vergonha.

Com relação a este sofrer, especificamente, percebemos que uma cultura que tende a desprezar as dimensões simbólicas da vida, inerentes a todas as formas de criatividade - estas intrínsecas às possibilidades 
de enfrentamento de qualquer condição adversa e/ou de sofrimento -, busca, assim, aviltadamente agir nas dimensões do real destes afetos, o que implica um esvaziamento simbólico que redunda infinitamente em torno de um vazio, o que, por sua vez, configura o semblante de um mundo que apreendemos como necessariamente patológico eis um dos vieses das perpetuações de condições de "mal-estar" e das (re)produções da alienação na contemporaneidade.

Por fim, o que podemos perceber é que o Campo de saberes, o qual os usuários dos mais variados tipos de serviços de saúde depositam suas esperanças de alívio/cura para seus males e aflições, sugere práticas que atuam como dispositivos normatizadores dentro da cultura vigente de nossos dias. Afinal, diante dos efeitos dos mais variados tipo de medicamentos, o sujeito enfim pode desfrutar de um convívio social satisfatório para um Outro sempre, pois dessa forma camuflam-se as ruminações pesadas e extremamente interiorizadas dos indivíduos que sentem singularmente o peso de sua existência.

\section{REFERÊNCIA BIBLIOGRÁFICA}

ANTUNES, A. Fora de si. In ANTUNES, A. Ninguém. Rio de Janeiro: BMG, 1995. 1 CD.

AULAGNIER, P. Os Destinos do prazer: alienação, amor, paixão. Rio de Janeiro: Imago, 1985.

BAUMAN, Z. O mal-estar da Pós-Modernidade. Rio de Janeiro: Jorge Zahar, 1998.

BIRMAN, J. Mal-estar na atualidade: a psicanálise e as novas formas de subjetivação. Rio de Janeiro: Civilização Brasileira, 2001.

BIRMAN, J. A psiquiatria como discurso da moralidade. Rio de Janeiro: Edições Graal, 1978. BOLGUESE, M. S. Depressão \& doença nervosa moderna. São Paulo: Via Lettera: Fapesp, 2004.
DEBÓRD, G. A sociedade do espetáculo. Rio de Janeiro: Contraponto, 1997.

FOUCAULT, M. Microfisica do Poder. Rio de Janeiro: Graal, 1979.

FOUCAULT, M. Os Anormais: curso no Collège de France. São Paulo: Martins Fontes, 2001.

FOUCAULT, M. História da loucura: na idade clássica. São Paulo: Perspectiva, 2005.

FREUD, S. Mal-estar na civilização. Obras Completas. São Paulo: Imago, 1992.

FREUD, S. O método psicanalítico de Freud. Rio de Janeiro: Imago, 1996. v. VII.

FREUD, S. Além do princípio do prazer. Rio de Janeiro: Imago, 1998.

KEHL, M. R. Sobre ética e psicanálise. São Paulo: Companhia das Letras, 2002.

LACAN, J. O seminário, livro 5: As formações do inconsciente. Rio de Janeiro: Jorge Zahar Ed., 1999.

LACAN, J. A Querela dos Diagnósticos. Rio de Janeiro: Jorge Zahar, 1989.

MINAYO, M. C. S. O desafio do conhecimento: Pesquisa qualitativa em saúde. São Paulo: Hucitec, 1996.

QUINET, A. (Org.). Psicanálise e Psiquiatria: controvérsias e convergências. Rio de Janeiro: Rios Ambiciosos, 2001.

VELOSO, C. It's a long way. In: VELOSO, C. Transa. Rio de Janeiro: Polygram, 1972. 1 CD. 